\title{
FAILING THE WALL OF MARGINALIZATION AND PROVIDING ELECTRICITY FOR ALL: DECISION MAKING ON SMART SYSTEMS INTEGRATION USING AHP
}

\author{
Fairouz Iberraken \\ Electrical Engineering Department, University of Bejaia, Algeria \\ fairouz.iber@gmail.com \\ Rabah Medjoudj \\ Electrical Engineering Department, University of Bejaia, Algeria \\ r.medjoudj66@gmail.com \\ Djamil Aissani \\ Operational Research Department, University of Bejaia, Algeria \\ lamos_bejaia@hotmail.com
}

\begin{abstract}
This paper aims to provide a tool to think creatively and to assist managers in their decision making to solve the problem of electricity unavailability. Three possible issues are exposed: insufficiency of power supply, law level of distribution system reliability and unpaid bills for the case of poor households. These problems lead to a reduced quality of life and create frustration of the population. There is an efforts combination of utilities' managers and the public authorities to support the problem, but the network must be communicating and admits smart meters that can apply the solution based on criteria specific to each situation. So it is appropriate to consider the integration of new technologies to the conventional network giving birth to a smart energy grid. The multi-criteria method of our choice is the Analytic Hierarchy Process (AHP), which is judged transparent and contributing to conflict resolution. It consists on developing the problem in a hierarchy, where tangible scenarios are considered in accordance with some criteria for which experts associate weights, got from a consensus.
\end{abstract}

Keywords: Decision Making, AHP, Smart Grids, Renewable energy.

\section{Introduction}

Electricity is an essential foundation for a sustainable world, and the integration of smart systems in the conventional network and the insertion of renewable energy resources provide a transition towards cleaner and environmentally sustainable technologies. This research work can be a driving force for the extension of the sustainable development theme. It is the origin of the idea to start training a Master in smart grids and sustainable electricity at Bejaia University. The successful outcome of this project can trigger the movement of other projects relevant to sustainable development. In this project, societal, environmental and economic indicators are highlighted; according to the specificity of each country to achieve sustainable electricity. It is developed, a correlation between electricity sustainability and both energy efficiency and quality of life. It is also stated that this topic must be supported under responsibility of a work group including experts in other fields such as civil and industrial engineering, economics and decision making aspects. Another aspect discussed and supported in this project is the profitability of the company providing electricity, coupled with a social side noting the need to solve the problem of unpaid bills of poor households. The main objective is to achieve a desired design, a fair and equitable model of sustainable electricity for developing countries such as Algeria where politics to go in the direction of sustainable development are ruffled, but there is lack of mechanisms ensuring a practical and evolutionary progress. Regarding its strategic location and its large deposit of sun, Algeria moves to clean energy development and smart 
grids integration to meet the dual objective of ensuring a better quality of service for consumers and reduce its energy dependence which is about $95 \%$ of fossil origin.

\section{State of the art on smart grids and their impact on society behaviour}

After dressing a review of the standards of the quality of life in developing and emerging countries it was found that the issue of sustainability is closely linked to the vision of development, to the management of strategies and to the membership of political, economic and social actors in citizenship and moralization of the society principles. Certainly any development needs a supply of investment, but it is not enough. Many of the concerned countries have a significant financial income, but the quality of life is still mediocre. For this we addressed several criteria and indicators in accordance to electricity sustainability. Several Developed countries have made considerable progress in the field of sustainable development and have published operated tools, such as smart grids integration and renewable energy resources insertion. It is easier and more appropriate for the decision makers in developing countries to take this opportunity to learn from experiences of others and follow the shortcuts. This saves time, makes economic tests, and increases the chances of projects achievement. Some models are followed such as: German model advocating research \& development and protection of the environment; Danish model which promotes the development of electric vehicles; Italian, Swedish and British models oriented towards the installation of smart meters. The American model in turn is directed toward the safety of power supply. However, French model was not motivated because the electric generation is nuclear not too inspired by the countries involved in this project. Smart grid was conceived and implemented in order to meet the challenges of power generation and several smart tools that have been developed to serve it. Modernization of the electric system will increase productivity, contribute to economic growth and the transition to cleaner technologies and environmentally sustainable as stated by NERC (2010). The future of energy production is dominated by renewable sources. But the success of integrating power from wind and solar sources depends on the ability of mastering the challenges due to their volatile and decentralized natures and to the mitigation of investment expenditures of their insertion to transport and distribution networks. The smart grid is a global concept with multiple perspectives, namely: technical, commercial, legal and societal. Many economists agree that the smart grid industry is experiencing a considerable growth with an annual rate approaching $23 \%$ and the back of the last five years will revolve around U.S. \$ 13 billion (Bouchot and Marcaux (2010)). Smart grid projects have contributed to the emergence of other services like computer security development, because the field of data transfer and communication has often been the target of terrorists and hackers.

\section{A sample of scenarios for AHP application}

The AHP is a tool for decision support. It allows managers to structure the complex problems they face in issuing judgments based on their experience and informal available data. The approach consists on: the identification of the goal, the development of potential scenarios that can meet the desired objective, the identification of the criteria and sub-criteria that influence the decision. In the following are developed the potential scenarios highlighted by the visions of different countries such as: the USA, China, India and Europeans. The decomposition of the problem in a hierarchy process is given in figure 1.

The European Commission supports numerous research and development on technologies for smart grids. Germany: focuses on research and development. The German government decided in 2006 to invest 15 billion euros in the project "E-Energy: ICT-based system Energy of the Future" to develop intelligence and networking technologies necessary to enable smart grids. Denmark: focuses on the development of electric vehicles. In the near future, an estimated onetenth of the entire Danish fleet will be electric or hybrid with investment plans implemented in the northern state. Spain: Iberdrola will invest 22 million euros in the STAR project, which will focus on the modernization of over 600 transformer substations and replacement of over 100,000 meters of 175,000 inhabitants of the city of Castellan. It will be the first Spanish city to integrate a smart grid. Therefore, 175,000 customers have a service improving power quality

Washington, D.C.

June 29 - July 2, 2014 
and reducing incidents. To achieve this, Iberdrola renew more than 100,000 meters currently serving its customers. Netherlands: Amsterdam Smart City project, launched in 2009, has a series of bold pilots could extend to the entire city and 700 units were equipped with smart meters, which measure energy consumption and $\mathrm{CO} 2$ emissions. Another example, an office tower will have an energy management system based on sensors that provide detailed information. Boats can be connected to electrical connection points, instead of running diesel generators. The municipality also intends to promote the electric car with the installation of recharging points. Amsterdam aims to satisfy, in 2020, 30\% of its energy needs through renewable energy, while the proportion is $6 \%$. Britain: The installation of 27 million meters was announced. The British project includes a number of high meters, due to the deployment of smart meters for both electricity and gas, allowing for better absorption of fixed costs of the project. Portugal: Inovgrid project, led by EDP approximately 6.1 million customers. Portugal receives steady winds and strong sunlight, so that some days, more than $90 \%$ of the electricity is produced from renewable energy sources. Today, more than 50,000 points of consumption are managed by smart grids in the country. Sweden: is an exception compared to other countries. Since 2001, studies on smart metering were conducted. The feature of this meter deployment is that it has not been regulated by law: indeed, the introduction of compulsory monthly billing based on actual consumption data from 1 July 2009 has created a strong incentive processing parks meter, low voltage, by Swedish operators. Indeed, at that time, 5.3 million smart meters have been deployed, mainly used for remote reading. The government does not exclude the possibility that some of the investments to be financed by an increase in the rate of the use of networks (regulated) and the measurement of benefits perceived by end users. In January 2011, 8 million smart meters were installed in Sweden. It aims to have a transport independent of fossil fuels by 2030, and for that, the park aims to develop electric vehicles. At present, only 317 electric cars are in circulation, whereas by 2020, 600,000 are planned. Builders have nonetheless begun to develop models. Saab has built a hundred test vehicles on the end of 2011, while Volvo plans to launch a plug-in hybrid. Switzerland: The research in electrical systems is operating in a relatively narrow landscape; the new agreement provides an essential contribution to a more intensive collaboration with its neighbours in the research. It allows for example the transfer of knowledge from large research projects such as the flagship E-Energy developed by Germany or enhanced coordination for norms and standards taking place soon enough. In this sense, it complements the international activities that Switzerland has in these areas from the International Energy Agency (IEA) and the European Union. Italy: Enel began installing the first smart grid in Italy, part of the impetus to develop the technology needed to manage the flow of electricity decentralized and fluctuating renewable energy sources. It said that several thousand customers will take part in 10 million euros pilot project in the southern region of Molise. France: French energy mix is dominated by nuclear with minimal $\mathrm{CO} 2$ emissions. The adoption of smart grids in France obeys to the following objectives: energy efficiency and service quality, seeking the adoption of a citizen attitude for reducing consumption and anticipating the success of the electric vehicle deployment with a large-scale renewable energy. Some regions set specific targets, such as reducing consumption of $15 \%$ by 2014 and reach a production-based renewable for about $25 \%$ of the total consumption mainly with their involvement in competitive clusters. The USA are currently at the forefront of green technologies and the country has committed to transform its antiquated electrical system "smart grid", a network full of computers and modelled on the architecture of the Internet. America takes an early lead in this area, which attracts huge investments and giants like IBM, Google, Cisco, Accenture General Electric and Siemens. Smart grids are expected to reduce electricity demand by $10 \%$ in the integrated network decentralized sources of renewable energy and reduce consumption peaks generators breakdowns and pollution. These technologies could avoid power outages that cost annually $\$ 80$ billion in the United States and reduce the energy bill of $\$ 150$ billion per year. Criteria highlighted to justify smart grid project are the reliability and security of supply. China: The economic growth in China has doubled its production capacity of electricity between 2004 and 2008. China plans to build a strong smart grid for a value of around 60 billion euros. Its network is remarkably different from the American and French networks, it is highly centralized and the Chinese smart grid is moving in a context of 
accelerating energy needs. India: smart grids in India have been implemented to improve energy efficiency. One example is to equip the substations with automatic recording systems equipped with advanced electrical test capabilities. For the processor, the system monitors the level of oil and temperature. Communication occurs through cellular networks with a central control and data acquisition. It should also minimize energy losses estimated at $30 \%$ of the total energy supported by the current Indian network. The blackout in September 2012 with its disastrous economic effects, gives a concrete way to the acceleration of the implementation of the smart grid project.

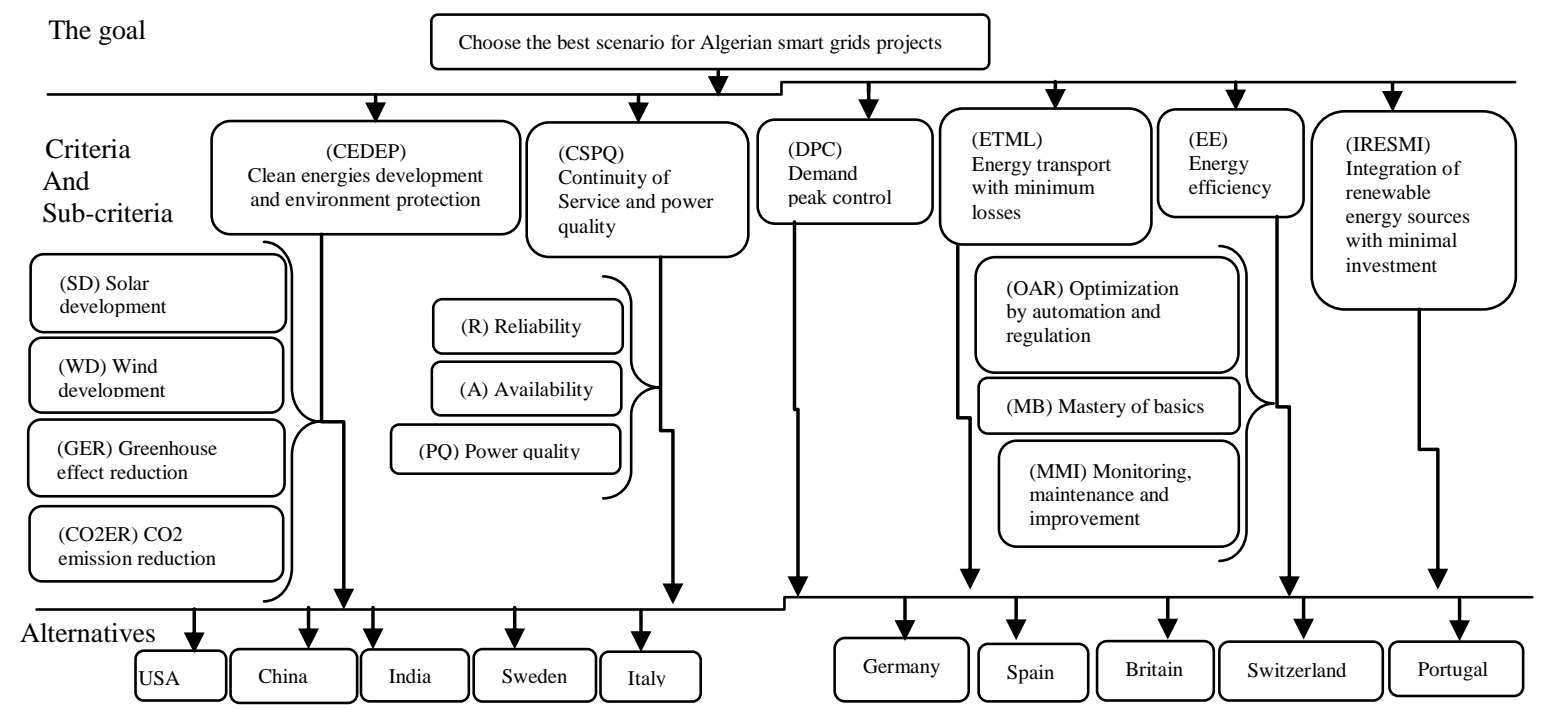

Figure 1: Decomposition of the problem into hierarchy process

\section{Algeria moves to smart grids projects}

Algeria is not immune from a new blackout and the terrible event of 2003 can be repeated. So we ask the recurring question: what is the space reserved to smart grids? Based on the earlier overview, smart grids highlight the following features: ability to perform forecast peak demand and to ensure its management; anticipation of the start of the emergency; risk assessment of equipment failures; management of shedding their workforce at the appropriate times and selection a priori of the consumer to relieve via power lines. The specific conditions of Algeria are: regulated market for electricity, monopoly environment and the majority shareholder is the Algerian state. SONELGAZ group suffers from the problem of the unpaid bills recovery. From one hand, to solve this problem in conjunction with illegal connections, it can enjoy the experience of Enel, which states that the invoice installation of smart meters was amortized using financial resources earned by limiting fraud. From the other hand, as it has the characteristic of public company, it is called to think on solving the problem of the most diminished household bills. It can sign an agreement with the government for the transformation of certain aid granted to electricity rations using prepaid cards that work on the smart meter or communicating counter. This can also help in counting the produced energy following the government decisions adopted to encourage individuals to produce their own clean energy. Several laws have been passed in relation to the energy conservation and the promotion of renewable energies in the context of sustainable development. More recently, the 2010 finance law has spent the creation of a national fund for renewable energy.

\section{Decision making using AHP method; the Algerian case}

The principles of AHP method are: the hierarchical structuring, Priorities structuring and logical consistency. The method includes the sensitivity analysis that gives the decision maker the possibility to change weights values of criteria or to eliminate whatever criteria it deems relevant. The criteria are: continuity of service and power quality; energy efficiency; control of peak demand; transporting over long distances with minimal losses; integration of renewable sources with minimum investment; decentralization and launch of electric vehicles; development of clean energy and environment protection. Given the advanced countries in the field of smart grids, we will help policy makers to 
draw models described in section 3. We have noticed a large heterogeneity in the projects. First, the French model deviates using the hypothesis of the dominance of the nuclear component. Second, the Danish model emphasizes electric vehicle performance which is not on the agenda of Algeria. In the weighting scenarios and criteria according to the timing given by Saaty (2008), we give high importance to actions under smart metering, clean energy development, reliability and quality of power and energy efficiency. Theoretical developments of the method have been already given in several recent articles published in similar contexts. This application constitutes a technical tool that can help policy makers and holders of SONELGAZ ambitions in smart grids projects moving. For the assessments, a computer program was developed at the LAMOS laboratory at the University of Bejaia and implemented under MATLAB software package. It has been verified that the program led to the same results given by the software marketed by Weteker and Adams (2005). The energy efficiency criterion was rated with a high priority given its technical and economic impact in the energy policy of each country. Given the invaluable presence of solar radiation in Algeria, a high priority is given to the production of solar energy, unlike wind. Reliability has received a very heavy weight compared to the power quality. After a series of standard calculations, namely pairwise comparisons between criteria and sub-criteria in relation to the goal, we have developed a synthesis, where the results are dressed in table 1. From this table, we deduce that the American model won the highest priority followed by emerging countries, such as China and India. In Europe, the Italian model seems most plausible. This is justified by the progress that recorded in the Enel smart metring. The German model is in a comfortable position in relation to energy efficiency and environment protection. In the study of the sensitivity analysis, we just provided a strong emphasis on the development of renewable energy (with high importance to the reduction of $\mathrm{CO} 2$ emissions) at the expense of energy efficiency and then we gave the same importance to the three components of the criterion. Despite the privilege accorded to the protection of the environment, the US model conserves at least the highest priority compared to the first results. This means that smart grids are very attentive to the problems of continuity of service and to the management of peak demands. As for European models, the German model is more sustained, followed by the Italian one.

Table1: Final results using synthesis

\begin{tabular}{|c|c|c|c|c|c|c|c|c|c|c|c|c|c|c|c|}
\hline $\begin{array}{l}\text { Criteria } \\
\text { Wrights }\end{array}$ & & $\begin{array}{l}\text { CEDEF } \\
0.2201\end{array}$ & & & & $\begin{array}{l}\text { C5PQ } \\
0.12015\end{array}$ & & $\begin{array}{l}\text { DFC } \\
0.0453\end{array}$ & $\begin{array}{l}\text { ETML } \\
0.0546\end{array}$ & & $\begin{array}{l}\mathrm{EE} \\
0.3706\end{array}$ & & $\begin{array}{l}\text { TRESMT } \\
0.1497\end{array}$ & $\begin{array}{l}\text { DEVL } \\
0.0388\end{array}$ & \\
\hline Sub-cintaik & SD & WD & GER & CO2ER & $R$ & A & $P Q$ & & & OAR & MB & MEII & & & \\
\hline Welghis & 0.5997 & e.1074 & 0.0930 & 0.1999 & 0.5936 & 0.2493 & 0.1571 & & & 0.1571 & 0.5936 & 0.2493 & & & Priarity \\
\hline USA & 0.1845 & 01326 & 0.0652 & 0.090 & 0.1650 & 0.1250 & 0.1260 & 03100 & 0,0569 & 01570 & 0.1060 & 0.1404 & 0.1120 & 0.0223 & 0.1300 \\
\hline China & 0.1921 & 0.1310 & 0.0562 & 0.0530 & 0.1120 & 0.1123 & 0.1120 & 00969 & 0.3116 & 01405 & 0.0498 & 0.1356 & 0.1396 & 00789 & 0.1225 \\
\hline India & 0.1546 & 0,0624 & 0.0432 & 0.0356 & 0.1370 & 0.1840 & 00980 & 03007 & 03249 & 01660 & 0.0270 & 0.1620 & 0.0560 & 0.0320 & 0.1122 \\
\hline Sweden & 0.0586 & 0.1312 & 0.1132 & 0.1290 & 0.1290 & 0.0850 & o. cosso & 0.0772 & 0.0675 & 00902 & 0.1925 & 0.1130 & 0.0896 & 0.1900 & 0.1195 \\
\hline lealy & 0.1130 & 00866 & 0.1001 & 0.1185 & 0.1210 & 0.1230 & 0.0888 & 0.0852 & 0.0310 & 0.1196 & 0.1396 & 0.1298 & 0.1428 & 0.1335 & 0.1201 \\
\hline Gemany & 0.1082 & 0.2325 & 0.1762 & 01378 & 0.0417 & 0.0989 & Q.1123 & 0.0345 & 0.0390 & 00040 & 0.1502 & 0,0523 & 0.1587 & 0.1565 & 0.114 \\
\hline Spain & 0.0321 & 0.0149 & 0.0745 & 0.1098 & 0.0405 & 0.0896 & 0.1019 & 00236 & 0.0396 & 00889 & 0.0943 & Q.1093 & 0.1065 & 0.0925 & 0.0773 \\
\hline Great Britain & 0.1120 & 0.0738 & 0.1123 & 0.1035 & 0.0918 & 0.0782 & 0.1022 & 00261 & 0.0463 & 0.0720 & 00720 & 0.0523 & 0.0510 & 0.0648 & 0.0745 \\
\hline 5 witremland & 00195 & 00741 & 01531 & 01212 & 0.0580 & 0.0428 & 00818 & 0.0269 & 0.0310 & 0.0610 & 0 cos 9 & 000520 & 0.0753 & 0.1343 & 0.0695 \\
\hline Potwgxil & 00253 & 00609 & 0.1060 & 01121 & 0.0517 & 0.0515 & acsi1 & 00280 & 0.0322 & 0.0508 & 0.0790 & 00536 & 0.0521 & 0.0950 & 0.0607 \\
\hline
\end{tabular}

\section{Conclusion}

Based on providing clean electricity for all, Algeria engages in the development of renewable energy and in the integration of smart systems in its conventional energy network. To assist decision-makers in the system management we have explored the above issue using the AHP method, with the experiences of other countries as alternatives and with criteria specific to SONELGAZ. The results are very promising, since it can hold three models that are easily adaptable to the Algerian conditions.

\section{References}

Bauchot F. et Marcaux B., (2010), Les visages des smart grids dans le monde. Instrumentation newsletters.

NERC, (2010), Reliability considerations from integration of smart grids, www.nerc.com.

Saaty LT., (2008), Decision making with the analytic hierarchy process, IJSS, 3(1); pp:83-97.

Whitaker R. and Adams W., (2005), Developers of SuperDecisions Software, Decisions Foundation, Pittsburgh, available at http://www.superdecisions.com. 